\title{
Analysis of nested tube type energy absorbers with different indenters and exterior constraints.
}

\author{
Edmund Morris $^{\mathrm{a}}$, A.G. Olabi ${ }^{\mathrm{a},{ }^{*}}$ and M.S.J. Hashmi ${ }^{\mathrm{a}}$
}

${ }^{a}$ School of Mechanical and Manufacturing Engineering, Dublin City University, Dublin, Ireland.

\begin{abstract}
.
The present work presents both numerically and experimentally the quasi-static lateral compression of nested systems with vertical and inclined side constraints. The force-deflection response of mild steel short tubes compressed using two types of indenter's is examined. The variation in response due to these indenters and external constraints are illustrated and how these can contribute to an increase the energy absorbing capacity of such systems. The implicit version of the Finite Element code via ANSYS is used to simulate these nested systems and comparison of results is made with those obtained in experiments and were found to be in good agreement.
\end{abstract}

Keywords: tubes, energy absorption, finite element, plastic deformation, lateral compression, quasi-static, ANSYS.

Notation.

A Area under the force-deflection curve

$e_{E} \quad$ Energy Efficiency

$e_{g} \quad$ Geometric or crush efficiency

$L_{o} \quad$ Original length (Outer diameter of outer tube)

$P_{\delta} \quad$ Peak load

$S_{s}^{c} \quad$ Specific energy absorption

$W_{\text {eff }} \quad$ Weight effectiveness 


\section{Introduction.}

In the study of energy absorbing systems and impact attenuation devices, rings/tubes have received a large amount of research due to its adaptability. An energy absorbing system may consist of a tube or system of tubes that are compressed laterally which absorbs the kinetic energy upon impact and hence dissipating it as plastic work. It is usually ideal in the design of these devices to absorb as much energy per unit mass. This can be done by introducing some form of side constraints which causes more plastic hinges to form on the component in question and hence an increase in the compression force.

Mutchler [1] analysed the energy absorbed by an aluminium tube compressed between rigid platens. The theoretical model was developed using a numerical integration scheme. The deformed contour consists of 2 circular arcs which are reduced as compression proceeds. These 2 arcs are connected by flattened segments which maintain their shape throughout the compression stroke.

DeRuntz and Hodge [2] also analysed the compression of a tube using limit analysis. A rigid perfectly plastic material model was used to predict the load deformation response. The geometrical component of stiffening was accounted for in the theoretical model. However the rate of increase was under-estimated, this was due to the material strain hardening phenomena. The deformed contour consists of four circular arcs which maintain their original radius and plastic deformation occurs in the hinges only.

Burton and Craig [3] examined this problem also and managed to predict a more rapid stiffening of the tube than proposed by DeRuntz and Hodge. The deformed shape is similar to that suggested by Mutchler.

Redwood [4] endeavoured to include the effects of strain hardening using the Burton and Craig model. A rigid linear strain hardening material model as opposed to a rigid perfectly plastic model was used to predict the force and energy absorption response.

The effect of strain hardening was further examined by Reid [5]. The theoretical model produced by the authors is based on a rigid linearly strain hardening material model and is the most accurate one to date. An improvement in the strain hardening prediction was achieved by replacing the localised hinges with an arc whose length changes with deflection. Hence this model accounts for both the geometrical and material strain hardening effect. An important dimensionless parameter was developed which governs the shape of the forcedeflection curve. This parameter is defined as $\mathrm{mR}$ and is a function of the yield stress in tension, the mean radius $\mathrm{R}$, the strain hardening modulus $\mathrm{E}_{\mathrm{p}}$ and the thickness $\mathrm{t}$. According to the author it may be possible to 
maximise the energy absorbing capacity by choosing appropriate tube dimensions such that the $\mathrm{mR}$ value is minimised since this is a function of tube geometry.

Reddy [6] examined both theoretically and experimentally the quasi-static lateral compression of a tube constrained so that its horizontal diameter is prevented from increasing. This is a way of increasing the specific energy absorption capacity of the tube by introducing more plastic hinges into the structure. Also the relationship between a single tube and a system of tubes with different configurations was investigated. It was found that the energy absorbed by a closed system (side constraints) is 3 times more than that of an open system (no constraints); however the maximum deflection of the former is less that that of an open system. Overall it can be concluded that the introduction of side constraints and creating a closed system is a feasible method of increasing its energy absorbing efficiency.

The introduction of inclined constraints as opposed to vertical ones can also increase the energy absorbing capacity of tubes/rings. Reid [7] examined the effect of varying the block angle for the lateral compression of tubes. It was shown how varying this angle also varies the character of the load deflection response.

The work described up to now involved the compression of tubes between rigid platens. However another way of compressing these systems is through point-load indenters as shown by Reid [8]. The load deflection for this type of compression tends to be unstable once the collapse load has occurred. This behaviour is termed deformation-softening as opposed to deformation-hardening (Rigid plates). The author examined the influence of strain hardening on the deformation of thin rings subjected to opposed concentrated loads. It was observed by the author that the role of strain hardening is important in the post collapse stage. During this type of compression as deformation proceeds, the moment arm increases therefore resulting in a decreasing load. This is termed an unstable response. However this instability can be controlled through the inclusion of material strain hardening, this is achieved by modifying the shape of the load deflection curve such that the value of the dimensionless parameter is less than 10. Fortunately it was recognised by the author that this instability vanishes for $\mathrm{mR}$ values (a function of tube dimensions) commonly encountered within energy absorbing devices.

Morris [9] analysed and presented some work on the post collapse response of nested tube systems with side constraints. The aim of this work was to show how the introduction of external constraints allows more volume of material within the structure to deform plastically in the post collapse stage of compression thereby 
absorbing more energy. Nested systems consist of 'short tubes' of varying diameter placed within each other with an eccentric configuration. To ensure that dynamic effects are not significant, a low velocity is applied to crush these systems. Both experimental and finite element techniques were used to analyse the response of such systems. Numerical results generated were in good agreement to those of experiment.

\section{Experimental Procedure.}

The experiments were carried out on the Instron Model 4204 testing Instrument for measuring the mechanical properties of materials and structures. A highly sensitive load is based in the moving crosshead of the loading frame and this measures the compression force of the specimen. 4204 series software is used to obtain the corresponding load deflection response. To stimulate quasi-static conditions the Instron crosshead had an applied velocity of $3 \mathrm{~mm} / \mathrm{min}$ thus taken approximately 40 minutes to compress the nested systems.

\subsection{Experimental Results: Flat plate Compression.}

Tubing can be classified as rings if its length is not greater than a few thicknesses or classified as a tube if its length is not less than its mean diameter. Hence the systems analysed here may be called 'short tubes', however for convenience all specimens will be referred to as 'tube' throughout the manuscript.

As already mentioned, Reddy [6] conducted experiments using external constraints as a means of increasing the energy absorbing capacity, Reid [7] analysed the compression of a tube using point indenters, hence the following analysis is an extension of their work in that both plate and point load indenters in conjunction with externals constraints are used.

Fig. 1a shows the double y-axis plot of crush force per metre and the specific energy absorbed versus stroke length for a 3 tube system with no external constraints imposed on it. Fig. 9a depicts how 3 tubes of varying diameter and each of length $60 \mathrm{~mm}$ were placed within each other to form a nested system of eccentric configuration. Due to this arrangement, an initial spacing of $17 \mathrm{~mm}$ and $21 \mathrm{~mm}$ exist between the tubes and it is when these gaps have established contact a rise in force will be observed. This rise in force is due to a combination of the 2 outer tubes stiffening and elastic deformation of the inner tube. Finally as the inner tube collapse the whole system begins to strain harden up to a maximum deflection of 116mm. As shown in Fig. 9a the upper and lower halves of the inner tube have began to touch. It is possible to increase the stroke length, however this may be seen as an over loading of the system and fracture may also occur. Also from the same figure, notice how only separation of the inner tube occurs while the remaining tubes stay in contact. 
(Note: units of displacement for all graphs are converted to $\mathrm{mm}$ for clarity.)

Fig. $1 \mathrm{~b}$ also exhibits a similar force deflection response however the specific energy has increased due to introduction of external inclined constrains of angle 15 degrees. These constraints cause more volume of material to deform particularly for the outer and central tube. Due to the design of the constraints, the compression stroke was stopped at $95 \mathrm{~mm}$ since the system began to deflect over the edges of the constraints as shown in Fig. 9b. This can be avoided by increasing the length of the blocks. However it should be noticed that little benefit would be achieved since fracture may occur around this magnitude of compression due to the sharp kinks that are formed.

Fig. 2a offers a plot consisting of the crush force and specific energy absorbed for a 3-tube system compressed between rigid plates and vertical side constraints. Photos consisting of the initial and final stages are displayed in Fig. 10a. The introduction of side constraints, which prevents an increase in the horizontal diameter of the outer tube during compression, causes more volume of material to deform plastically as already established by Reddy [6]. Notice how at approximately $55 \mathrm{~mm}$ deflection there a rapid rise in force, this behaviour is due the stiffening of outer tube since it has conformed to the shape of the vertical side constraints while at the same time the central tube prevents it from collapsing inward.

A crush force and specific energy response graph for a system compressed between rigid plates with both vertical and side constraints is shown in Fig. 2b. The resulting crush force has again increased as expected due to introduction of extra constraints. A rapid rise in force occurs at approximately $48 \mathrm{~mm}$ and this is also due to the horizontal diameter of the outer tube from deflecting from increasing. Fig. 10b depicts the various stages of compression for this system.

\subsection{Experimental Results: Point-load indenter.}

Fig. 11a provides illustrations of the various stages of a 3-tube system compressed with a point load indenter without any external constraints. Notice symmetry is lost between the upper and lower halves of all tubes due to compression between a single rigid plate and single point indenter. The corresponding force and energy response is depicted in Fig. 3a. The collapse force of each tube is similar in magnitude to that of the 3-tubes system compressed between rigid plates. Once the inner tube has collapsed the whole system begins to soften as opposed to strain hardening, thus there appears to be instability within the system and is due to an increase in the moment arm, this result's in a reduction in the force required to maintain the deformation Reid [8]. At 
approx $116 \mathrm{~mm}$ deflection onwards there appears to be a rise in force, this is due to the adjacent faces of the indenter obstructing the outer tube. This can be confirmed in the photos of Fig. 11a.

Fig. $3 b$ offers the crush force and specific energy response of a 3-tube system with 15 degree inclined constraints. The resulting force has increased slightly due to introduction of side constraints. In the post collapse stages of the inner tube (at approximately $48 \mathrm{~mm}$ ) the system is unstable for the remaining deflection. Compression of this system is illustrated in Fig. 11b. Notice how for the final stage of deformation the inclined constraints cause a greater interference of the adjacent sides of the indenter with the tube.

Fig. 4a and Fig. 12a show results of a 3-tube system compressed with vertical side constraints. Upon inspection of Fig. 4a we see how the central tube begins to soften before it establishes contact with the inner tube. This softening appears to be more excessive in contrast to all of the above-mentioned systems. Once collapse is initiated in the inner tube the system softens for the remainder of deflection. Again a rise in force is observed due to presence of the indenter obstructing the outer tube.

The final experiment consists of a 3-tube system with both vertical and inclined constraints as shown in Fig 4b. Fig. 12b shows the corresponding force and specific energy response for this system. At approximately $115 \mathrm{~mm}$ deflection a rapid rise in force is observed due to the reasons mentioned in the preceding paragraph.

Note that for all systems compressed with a point load indenter the crush efficiency can be maintained at approximately $70 \%-80 \%$ and possibly more provided a narrower point indenter is used in order to avoid interference with the outer tubes.

\section{The Finite Element Method.}

For the finite element model the implicit time integration scheme as opposed to the explicit method was used since all testing were carried under static conditions. Elements used were 3-dimensional 20 node structural solid elements of tetrahedral shape. All models contain 3 non-linearities namely (1) material non-linearity (2) contact status and (3) large deflection large strain deformation. A bilinear isotropic hardening model was used to capture the strain hardening effects in the plastic stages of deformation., Two contact classifications were used: Rigid to Flexible and Flexible to Flexible. The former was used to simulate contact between the rigid plate/point indenter surface and the outer tube while the latter was used to simulate the remaining 2 contact pairs. All contact pairs models were of surface to surface orientation. Since deflections are approximately $60 \%$ to $80 \%$, the tube systems will experience changes in its volume hence this must be accounted for as a 
geometric non-linearity in the Finite Element Code. The various indenters used to compress the systems were defined as rigid bodies and constrained to translate vertically over a predefined displacement. Table 1 shows the geometric and material information of the tubes used in both the experiments and numerical models. Symmetry boundary conditions were imposed on all models to speed up solution and hence the corresponding reactive forces were multiplied by their appropriate factor. Plastic modulus of $1.5 \mathrm{GPa}$ was used to represent the plastic region of the stress-strain curve for the 3 different tubes analysed. This value was also used by Reid [10]. One possible way of improving or confirming present numerical results is to cut a sample specimen from the tube stock and perform tensile test to obtain the stress-strain curve. This curve can be converted to a true stress strain plot and input to the Finite element code as a 'multilinear' material model. It should be noted that although the bi-linear material model is only an approximation, the results obtained are very satisfactory.

\section{Comparison of Numerical results with those of Experiments.}

Fig. 5a, 5b, 6a, 6b, 7a, 7b, 8a and 8b show the comparison of results between the numerical solutions offered by Ansys and those observed by Experiment. For all results except Fig 6a, 6b the numerical solution tends to under-predict the collapse force followed by an over-prediction for the remainder of the stroke. This over prediction is due to the use of a bilinear material model which assumes the flow stress to increase indefinitely as the strain increase however his does not happen in real conditions. Fig. 6a, 6b show excellent predictions of the actual response for these types of systems.

Fig. 13a, 13b, 14a, 14b, 15a, 15b, 16a and 16b show the graphic plots the various tube systems compressed. These can be compared where relevant to Fig. 9a, 9b, 10a, 10b, 11a, 11b, 12a, 12b. Notice how Ansys, in Fig. $13 \mathrm{a}, 13 \mathrm{~b}$ accurately predicts the separation of the inner tube from its surrounding environment while the remaining 2 tubes conform to the shape of the external constraints. Also in Fig. 14b the actual separation of the outer tube from the rigid plate is accurately predicted. It should be noted however upon comparison of the graphic plots to those of experiment, that in the final stages of deformation, the hinges predicted by Ansys are quite curved as opposed to a slight kink as observed in the experiments. This slight difference is due to the bilinear material model which does not consist of any fracture parameters and hence ANSYS predicts excessive 'ductile' deformation to occur without any incidence of fracture. 


\section{Energy absorption Characteristics.}

It is usual to describe the behaviour of energy absorbing systems in terms of performance indicators. Thornton [11] suggested indicators such as crush efficiency, energy efficiency, specific energy absorption capacity and weight effectiveness that may be useful in describing the performance of absorbing systems. Table 2 gives an outline of the various performance indicators used to describe the response of the various systems tested. For systems A-D it can be seen how the crush efficiency decreases due to existence of external constraints. For systems E-H (point load indenter), it is possible to maintain a crush efficiency between $70 \%-80 \%$, therefore it can be observed that the use of external constraints has much less of an impact on the crush efficiency. The energy efficiency of the various systems compressed is also shown. Energy efficiency as described by Thornton [11] is given as

$$
e_{E}=\frac{A}{P_{\delta} * L_{o}}
$$

where A is the area under the force deflection curve, $P_{\delta}$ is the peak load observed and $L_{o}$ is the original length. Upon examination of this equation, it can be seen that to achieve $100 \%$ energy efficiency requires a rectangular force-deflection curve or a rigid perfectly plastic force-deflection response. From a practical point of view, to achieve maximum energy efficiency, the force-deflection response needs to be adjusted so the peak force will occur in the early stages of deflection and preferably remaining at this magnitude for the remainder of the stroke. This is an ideal requirement in the design of energy absorbing systems since the deceleration force is desired to be kept to a minimum. By examining systems A-D, it can be seen that the energy efficiency is quite low particularly for C and D. This is because the peak force occurs at the final stage of deflection as opposed to the early stages. Systems E-H show higher energy efficiencies, this is due to the peak force remaining constant or decreasing for the remaining stroke length. Although the systems E-H show better crush and energy efficiencies, 2 points need to be addressed. Firstly, the specific energy absorption capacity of the systems compressed with a point load indenter is smaller since less volume of material is exposed to plastic deformation. Secondly and more importantly point load compression causes a softening to occur as already explained previously therefore reducing the systems energy absorbing ability.

A final performance indicator that may be used to describe the behaviour of such systems is the weight effectiveness, which is given as 


$$
W_{e f f}=e_{g} * S_{s}^{c}
$$

where $e_{g}$ is the crush efficiency and $S_{s}^{c}$ is the specific energy absorption capacity. It is a useful indicator since the relative energy absorption capacity of the system is used in conjunction with an important variable, the stroke length.

From table 2 it can be seen how, system A-D (flat plate compression) results in higher specific energy absorption than those systems E-H (point load indenter), however, due to their low crush efficiencies, the overall weight effectiveness of the former systems is somewhat reduced significantly. For the remaining systems E-H, the overall effectiveness remains close in magnitude to those compressed under a rigid flat plate. This is due to the high crush efficiencies that are achievable when using a point load indenter.

\section{Conclusion.}

Experimental investigations into the compression of nested systems under 2 different loading conditions have been conducted. The configuration of these systems described previously can prove to be advantageous in such cases where space is a very important design parameter as well as maintaining maximum energy absorption.

Different variations of external constraints have been used as a means of increasing the energy absorbing capacity of these nested systems. Although the constraints increase the specific energy of both systems A-D and E-H, the crush efficiency of the former suffers as a consequence and hence the weight effectiveness is somewhat reduced. It is possible to achieve reasonably high crush efficiencies when a point load indenter is used. However the designer should be aware of the softening phenomenon that occurs with this type of system, since this may not be a desirable feature in the design of energy absorbing systems.

Comparison of the results from both experiment and finite element methods has been analysed. The numerical results were found to be well behaved and quite satisfactory in comparison to those of experiment. Such energy absorbing devices may find application where the structural body in question is subjected to compressive loads during impact. Examples being bumpers attached to cars and trucks. Other applications such as crash barriers, aircraft fuselages, oil tankers also require energy absorbing devices for obvious safety reasons. 
References.

[1] Mutchler LD. Energy absorption of aluminium tubing. Transactions of ASME, Journal of Applied Mechanics 1960; 27:740-743.

[2] DeRuntz JA, Hodge PG. Crushing of a tube between rigid plates. Transactions of ASME, Journal of Applied Mechanics 1963; 30:391-395.

[3] Burton RH, Craig JM. An investigation into the energy absorbing properties of metal tubes loaded in the transverse direction. B.Sc. (Eng) Report, University of Bristol, Bristol, England (1963)

[4] Redwood RG. Discussion of Ref. 3. Transactions of ASME, Journal of Applied Mechanics 1964; $31: 357-358$

[5] Reid SR, Reddy TY. Effect of strain hardening on the lateral compression of tubes between rigid plates. International Journal of Solids and Structures 1978; 14:213-225.

[6] Reddy TY, Reid SR. Lateral compression of tubes and tube-systems with side constraints. International Journal of Mechanical Sciences 1979; 21(3) 187-199.

[7] Reid SR. Laterally compressed tubes as impact energy absorbers. Chapter 1 Structural Crashworthiness. (Editors: Jones N, Wierzbicki T), Butterworths, London.

[8] Reid SR, Bell WW. Influence of strain hardening on the deformation of thin rings subjected to opposed concentrated loads. International Journal of Solids and Structures. 1983 18; 643-658.

[9] Morris E, Olabi A, Hashmi S. Post collapse response of nested tube systems with side constraints. In: Challenges facing manufacturing. 22nd International manufacturing conference, Dublin. 2005 p. 693-700.

[10] Reddy TY, Reid SR. Phenomena associated with the crushing of metal tubes between rigid plates. International Journal of Solids and Structures 1979 16; 545-562. 
[11] Thornton PH. Energy absorption by structural collapse. Chapter 4 Structural Crashworthiness.

(Editors: Jones N, Wierzbicki T), Butterworths, London. 1993.

*Corresponding Author: A.G. Olabi. Tele: +353 1700 7718, Fax: +353 1700 5345. email. abdul.olabi@dcu.ie 


\section{Crush Force per metre, Specific Energy versus Displacement}

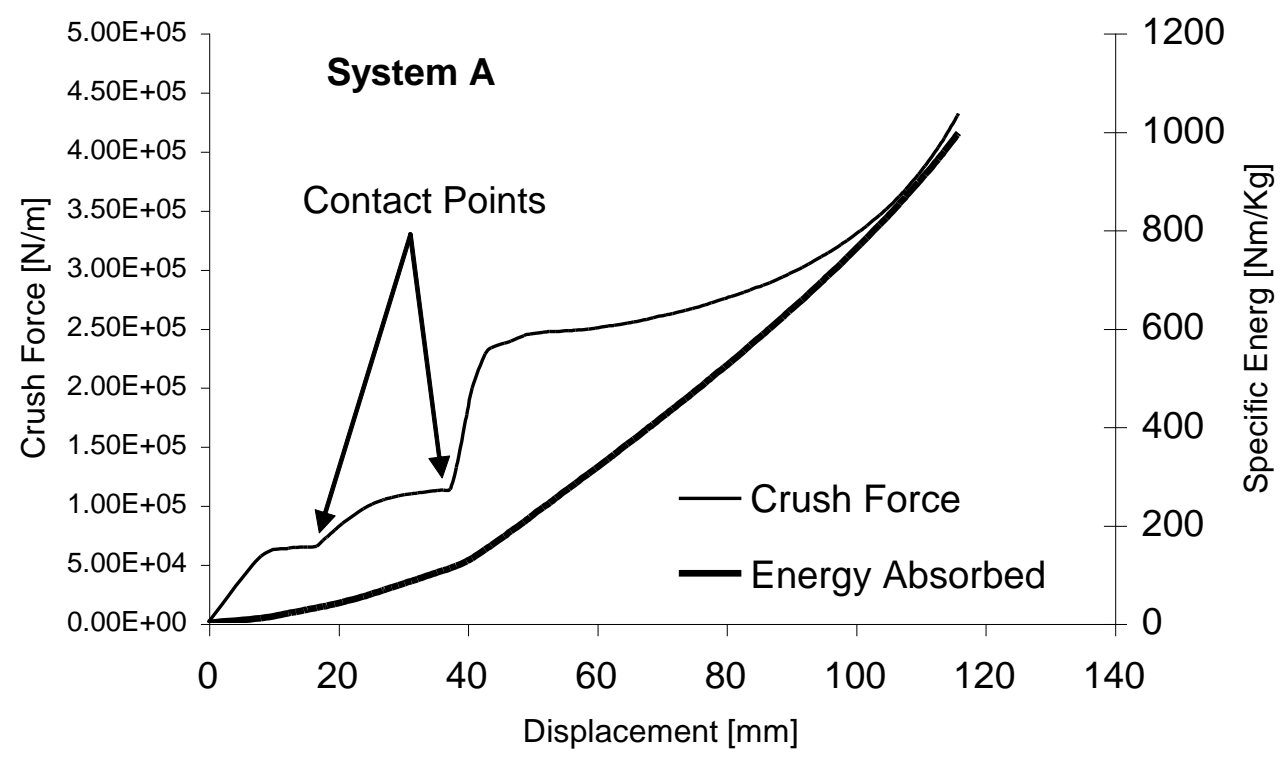

Fig. 1a. Load-displacement plot of an assembly of 3 tubes under flat plate compression. 
Crush Force per metre, Specific Energy versus Displacement

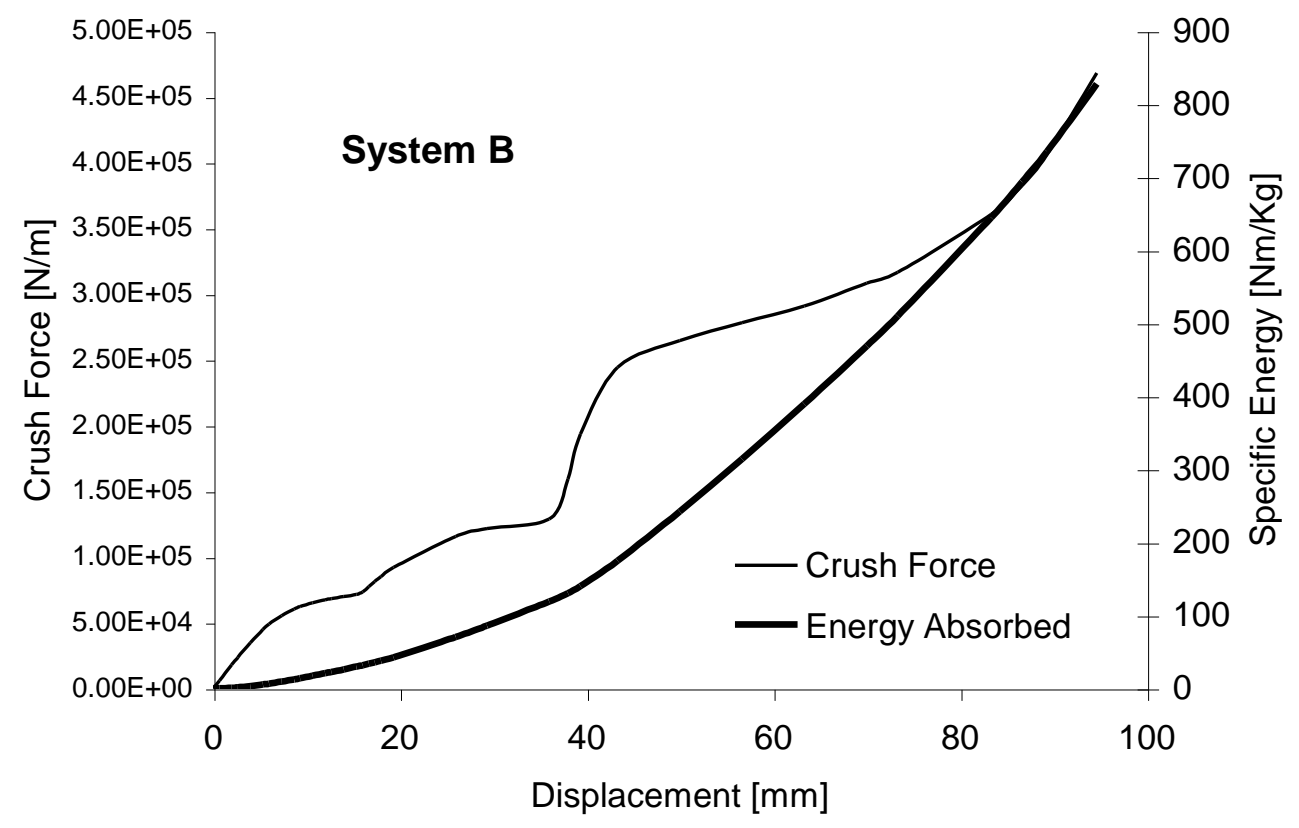

Fig. 1b. Load-displacement plot of an assembly of 3 tubes under flat plate compression with inclined constraints. 


\section{Crush Force per metre, Specific Energy versus Displacement}

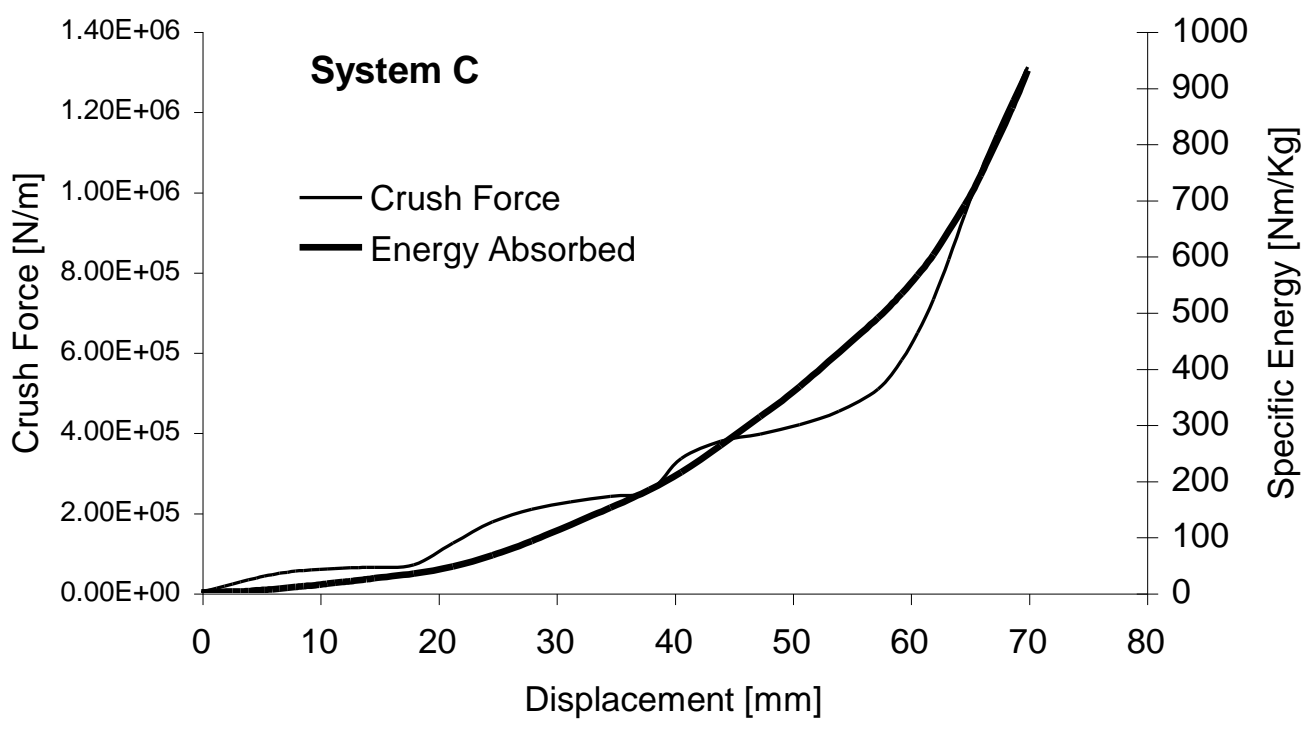

Fig. 2a. Load-displacement plot of an assembly of 3 tubes under flat plate compression with vertical side constraints. 


\section{Crush Force per metre, Specific Energy versus displacement}

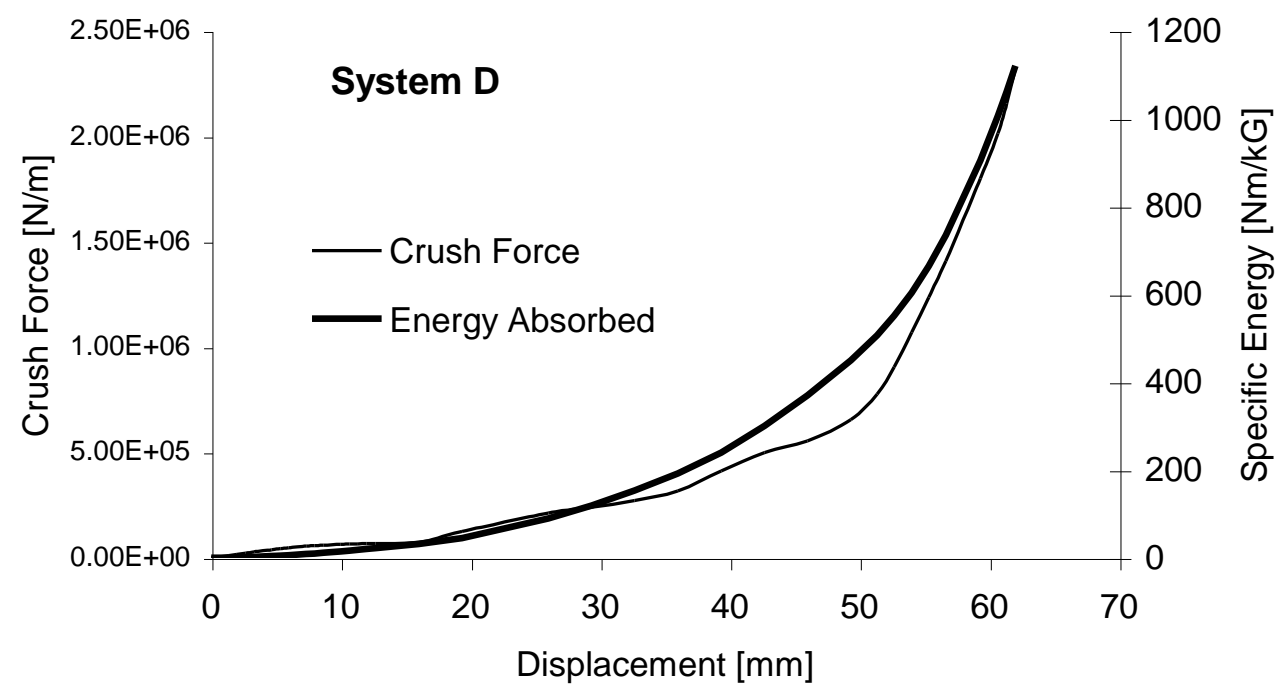

Fig. 2b. Load-displacement plot of an assembly of 3 tubes under flat plate compression with vertical and inclined constraints. 
Crush Force per metre, Specific Energy versus Displacement

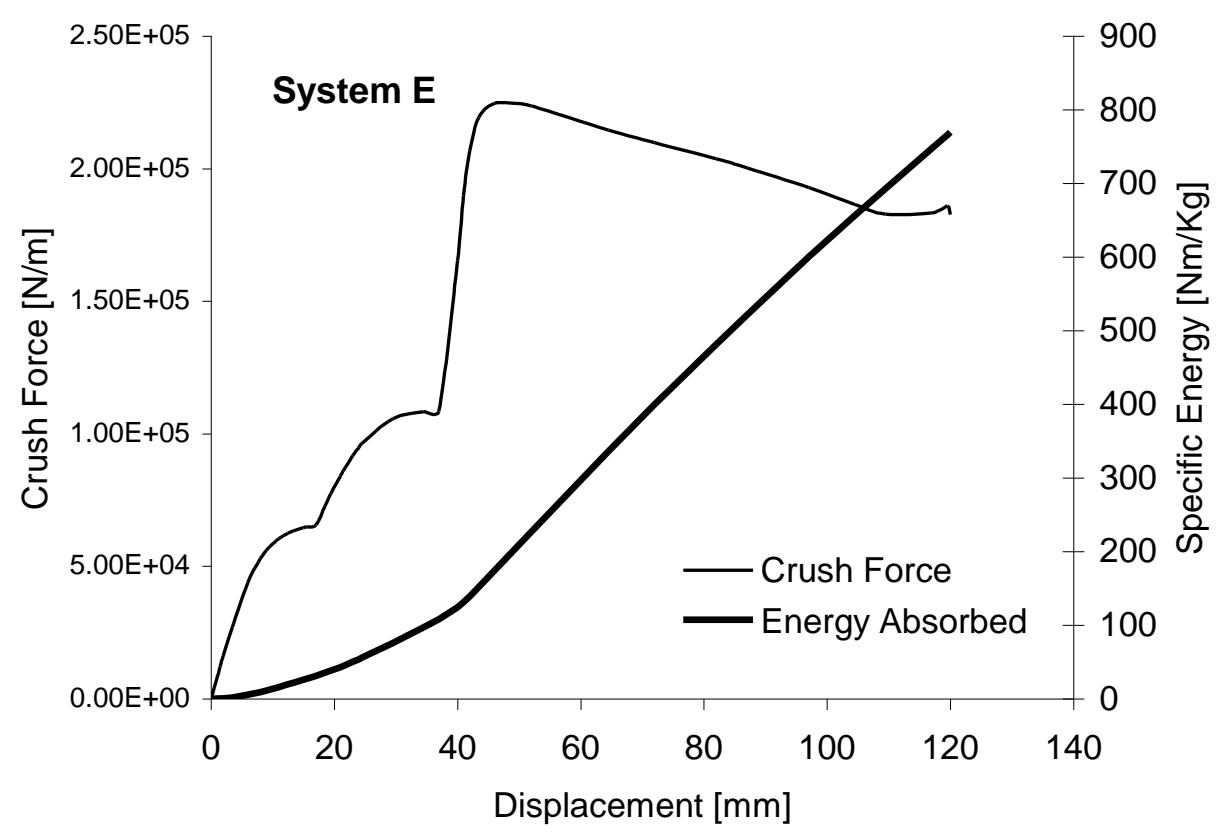

Fig. 3a. Load-displacement plot of an assembly of 3 tubes under point load compression with no constraints. 
Crush Force per metre, Specific Energy versus Displacement

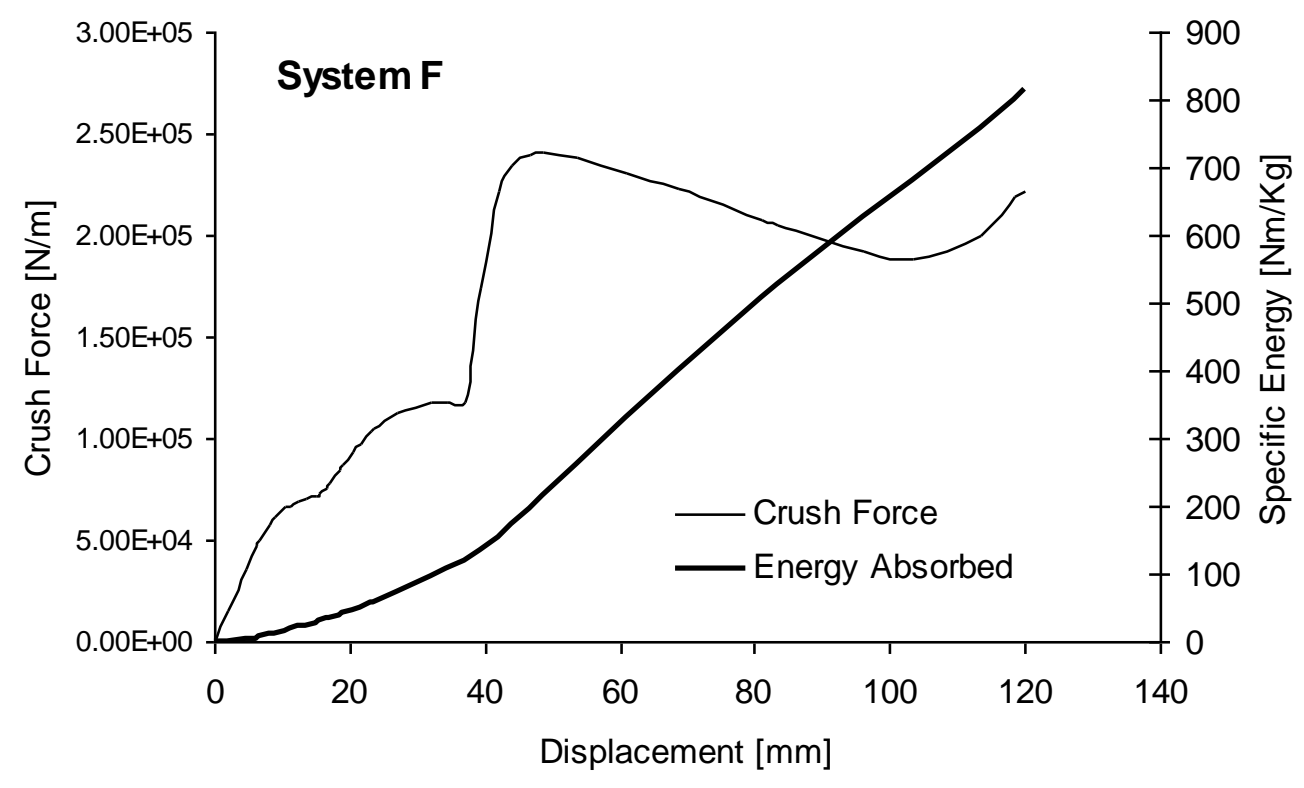

Fig. 3b. Load-displacement plot of an assembly of 3 tubes under point load compression with inclined constraints. 


\section{Crush Force per metre, Specific Energy versus Displacement}

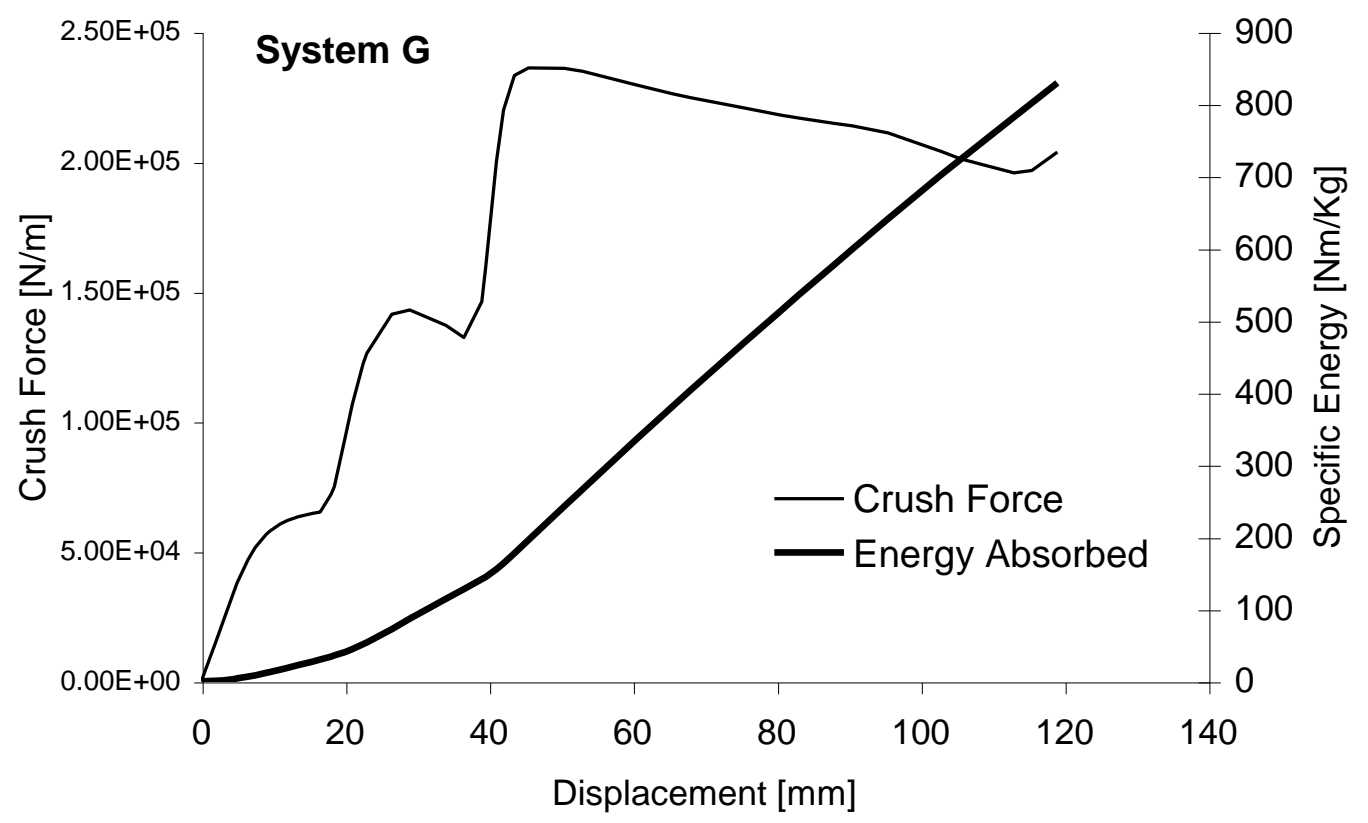

Fig. 4a. Load-displacement plot of an assembly of 3 tubes under point load compression with vertical side constraints. 


\section{Crush Force per metre, Specific Energy versus Displacement}

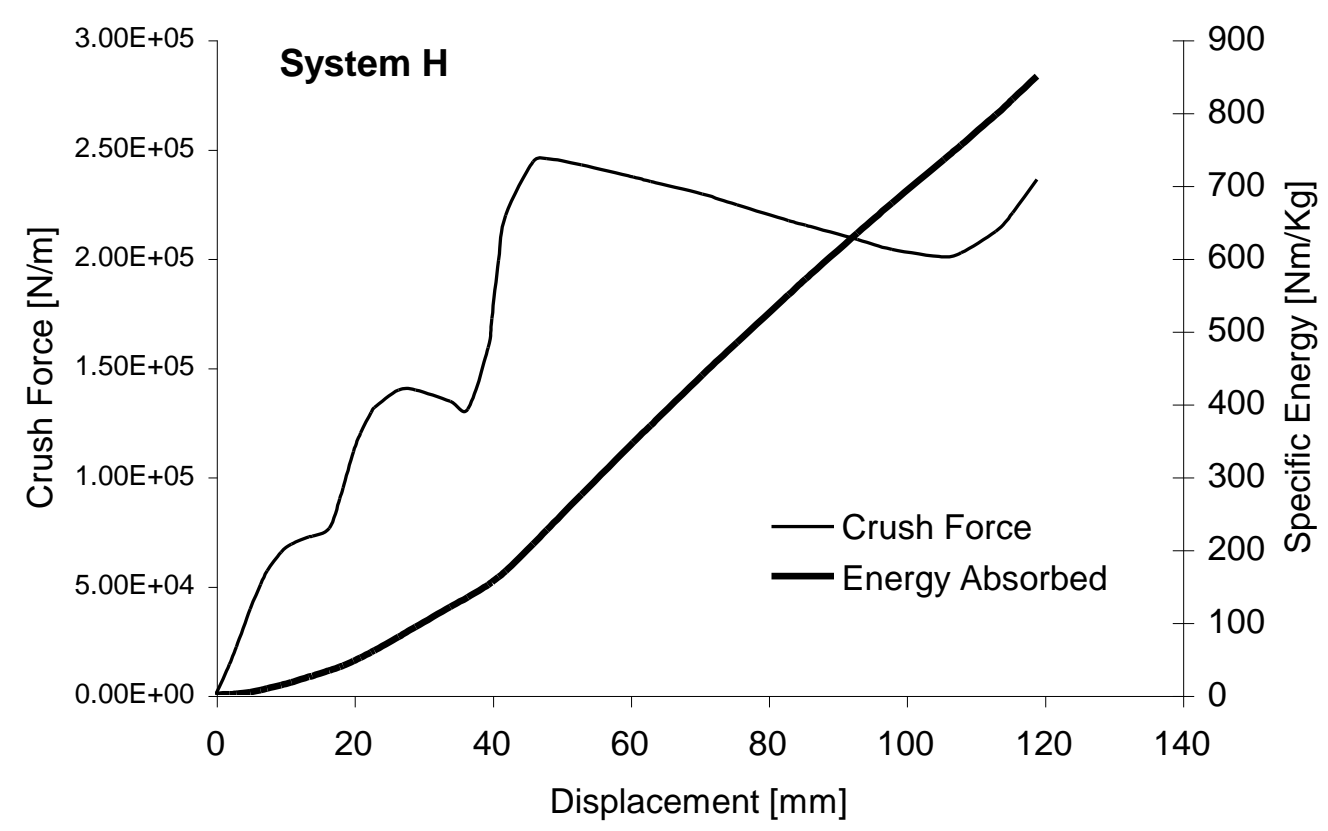

Fig. 4b. Load-displacement plot of an assembly of 3 tubes under point load compression with inclined and vertical side constraints. 


\section{Crush Force, Specific Energy absorbed versus Displacement}

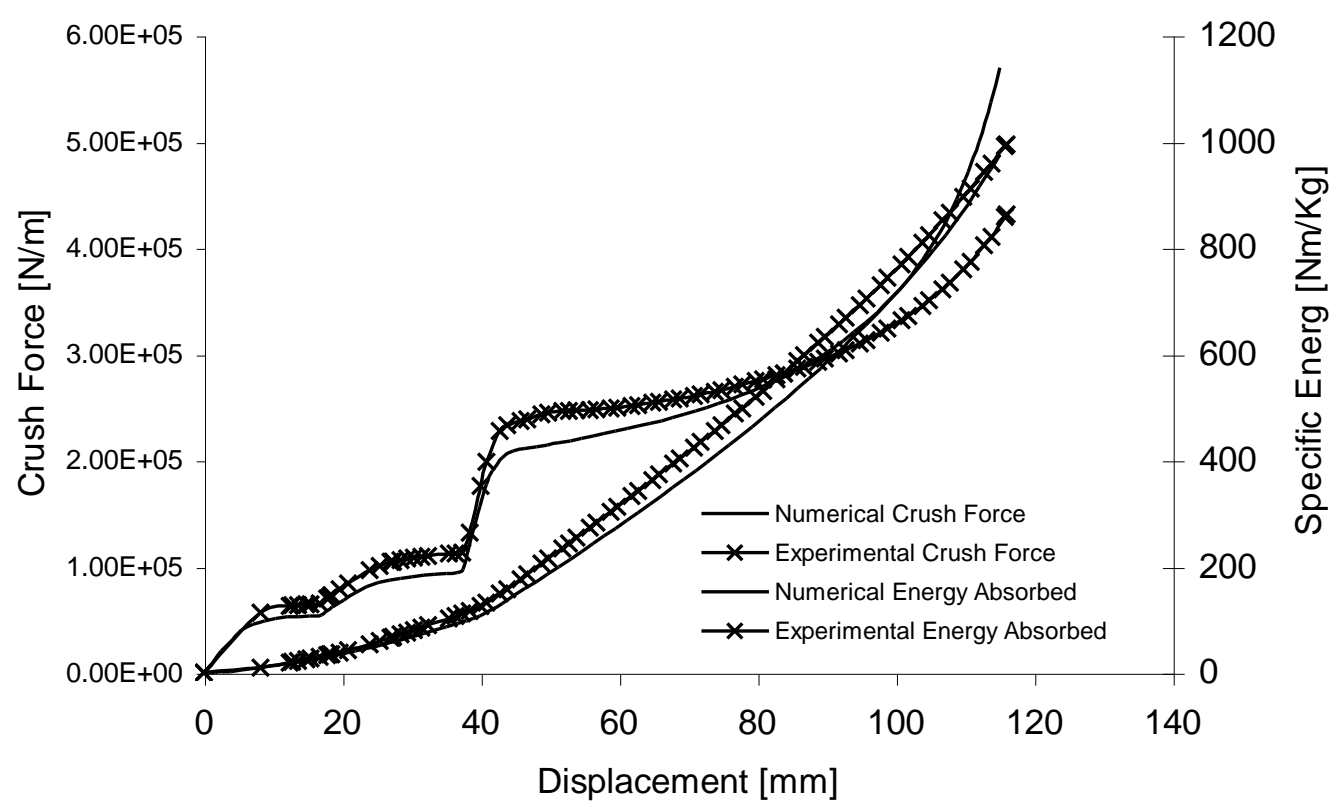

Fig. 5a. Experimental results and numerical solutions for a 3 tube assembly compressed between rigid plates and no constraints. 


\section{Crush Force, Specific Energy versus Displacement}

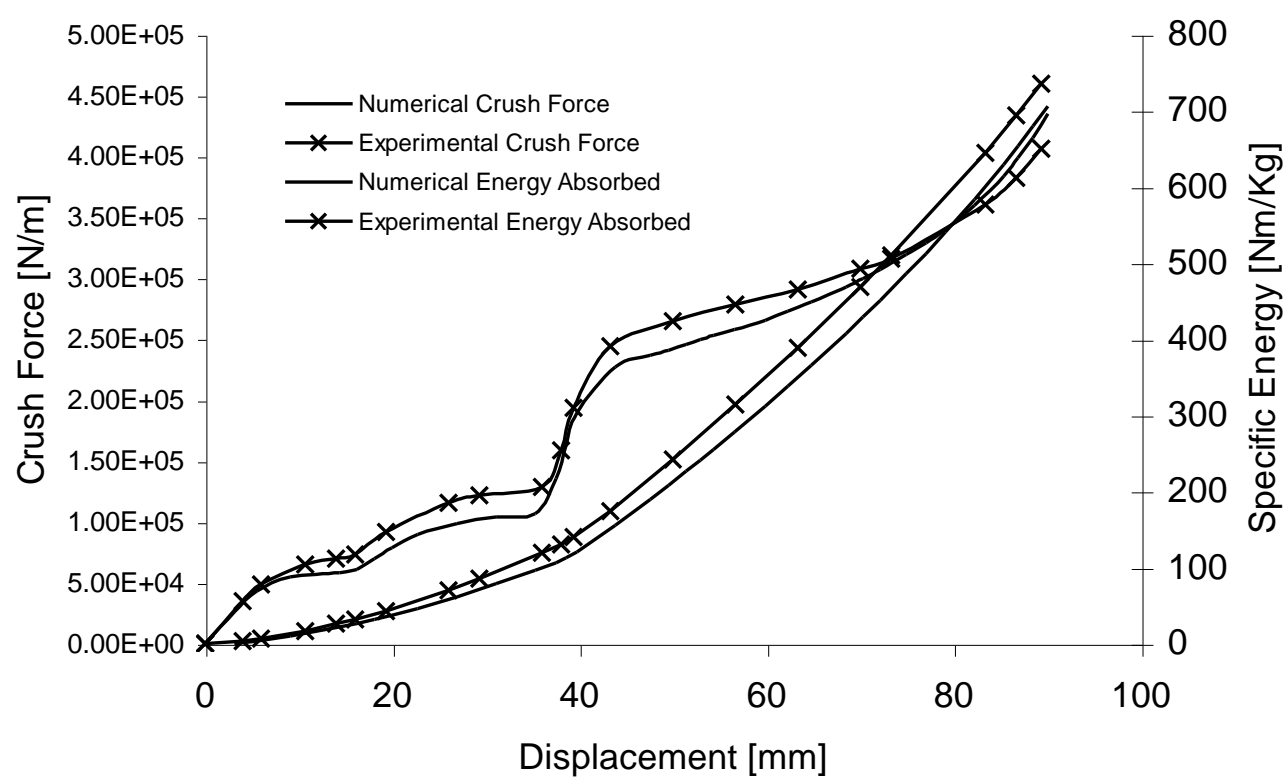

Fig. 5b. Experimental results and numerical solutions for a 3 tube assembly compressed between rigid plates and 15 degree inclined constraints. 
Crush Force per metre, Specific Energy versus Displacement

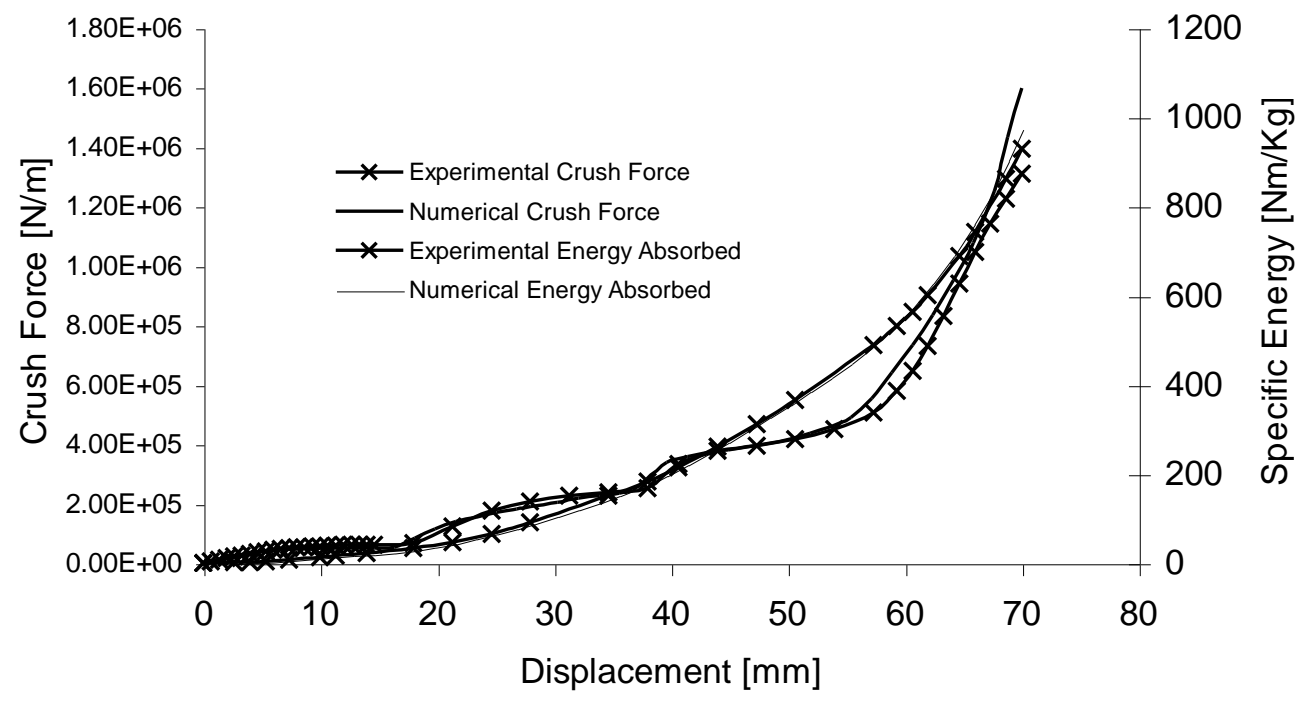

Fig. 6a. Experimental results and numerical solutions for a 3 tube assembly compressed between rigid plate and vertical side constraints. 
Crush Force per metre,Specific Energy versus displacement

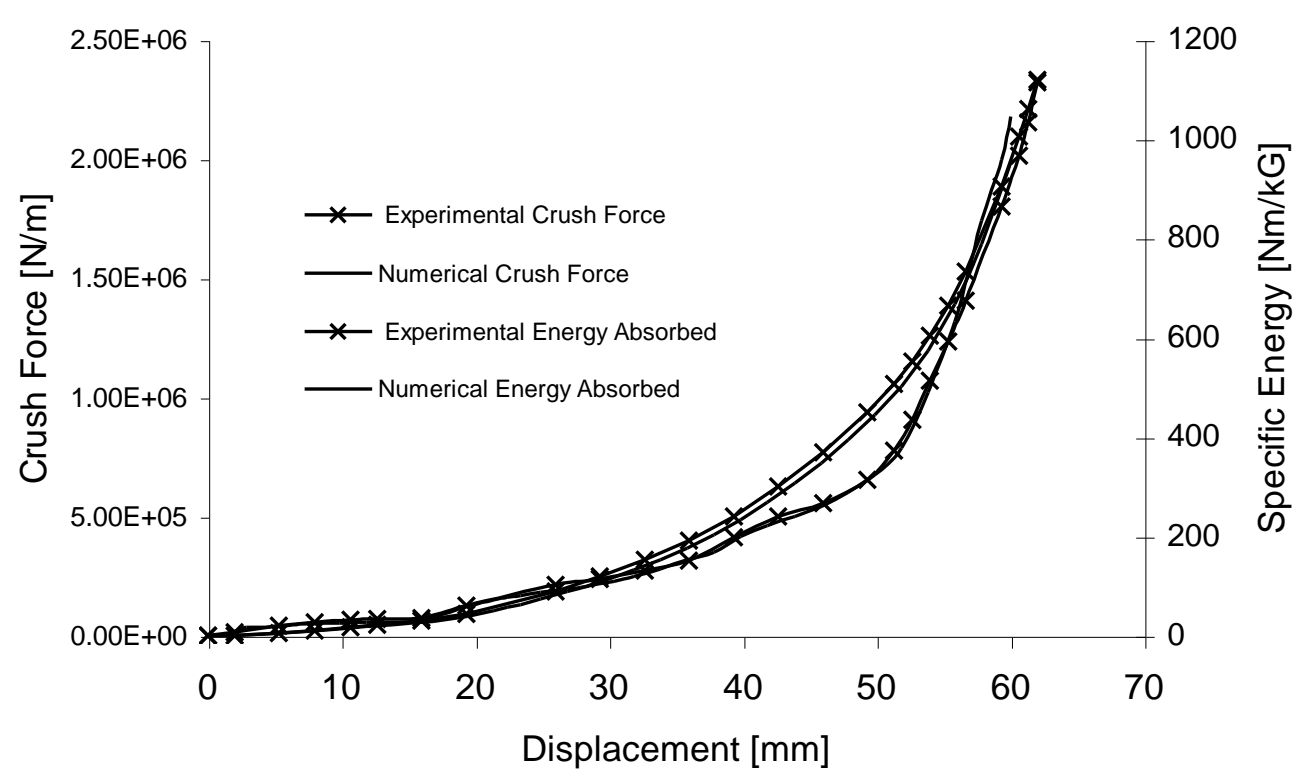

Fig. 6b. Experimental results and numerical solutions for a 3 tube assembly compressed between rigid plates, vertical and inclined constraints. 
Crush Force per metre, Specific Energy versus Displacement

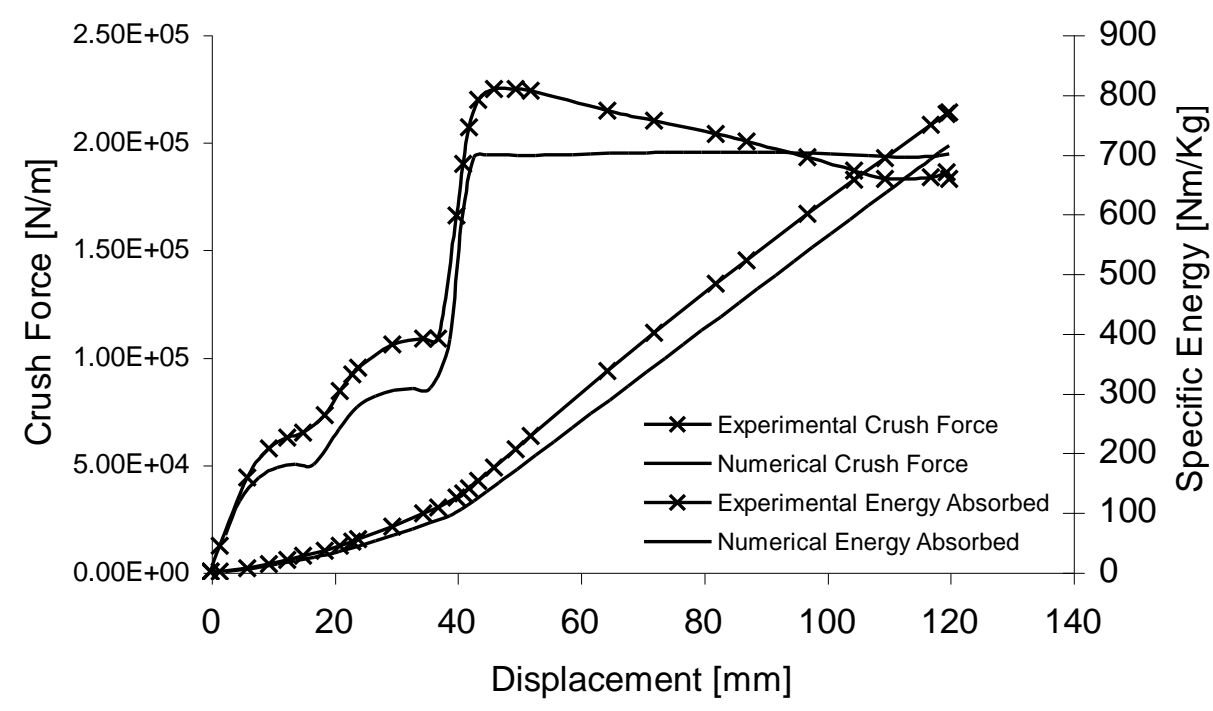

Fig. 7a. Experimental results and numerical solutions for a 3 tube assembly compressed by a point indenter and no constraints. 
Crush Force per metre, Specific Energy versus Displacement

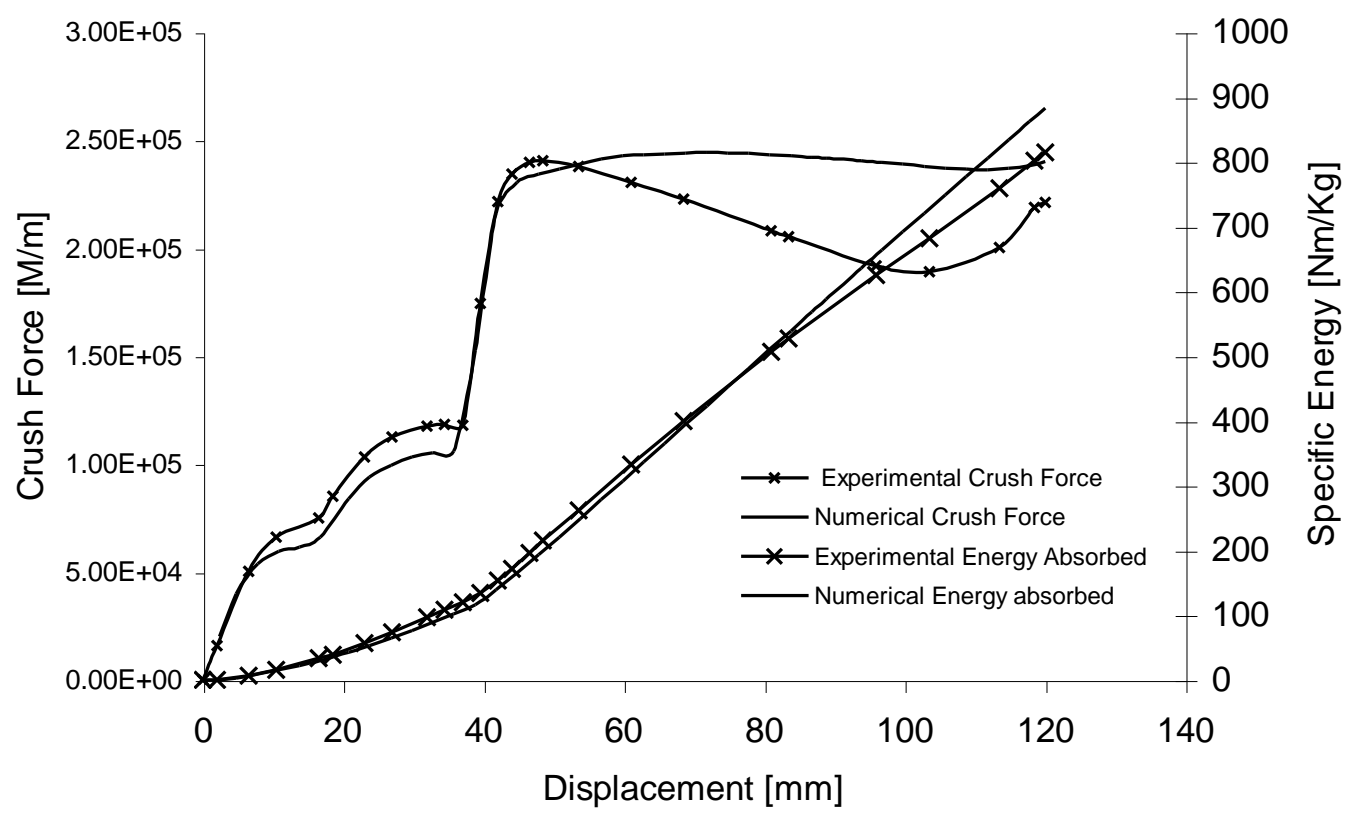

Fig. 7b. Experimental results and numerical solutions for a 3 tube assembly compressed by a point indenter and 15 degree inclined constraints. 


\section{Crush Force per metre, Specific Energy versus Displacement}

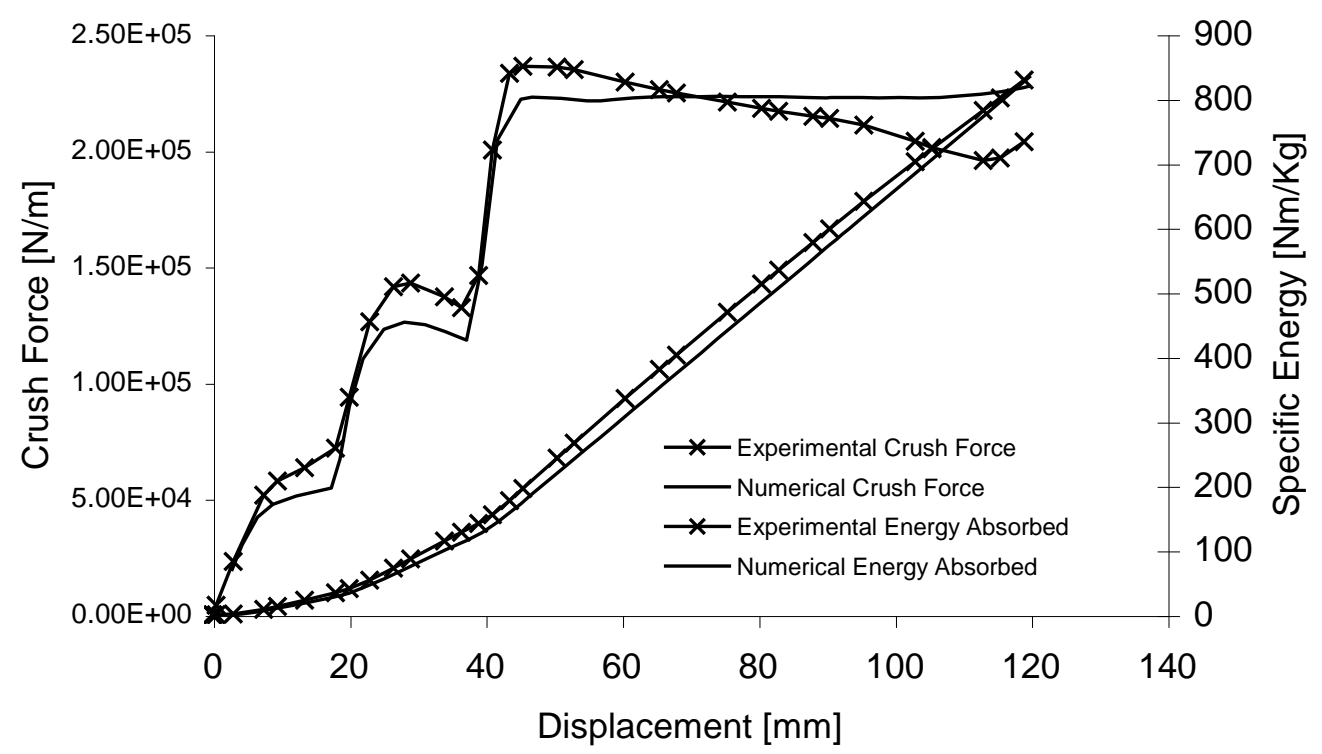

Fig. 8a. Experimental results and numerical solutions for a 3 tube assembly compressed by a point indenter and vertical constraints. 
Crush Force per metre, Specific Energy versus Displacement

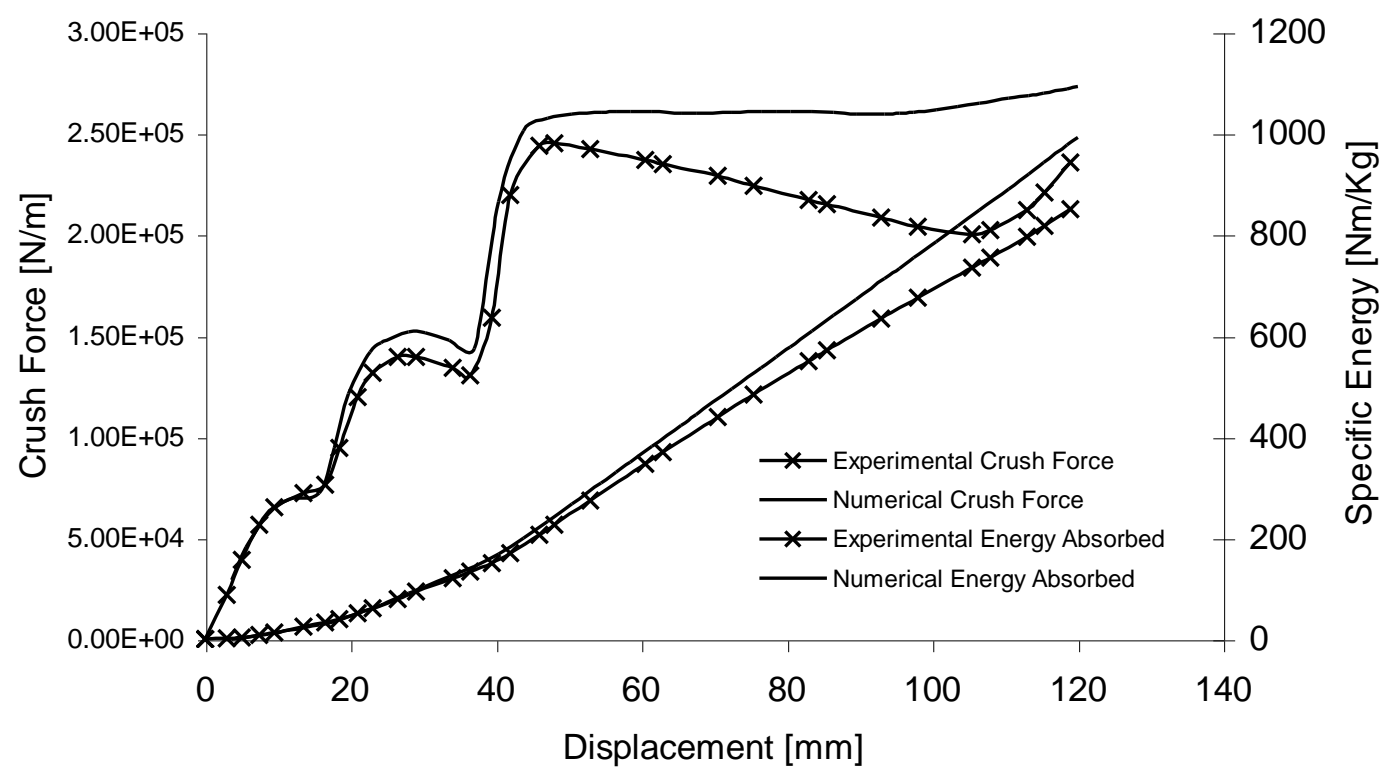

Fig. 8b. Experimental results and numerical solutions for a 3 tube assembly compressed between by a point indenter, vertical and inclined constraints. 


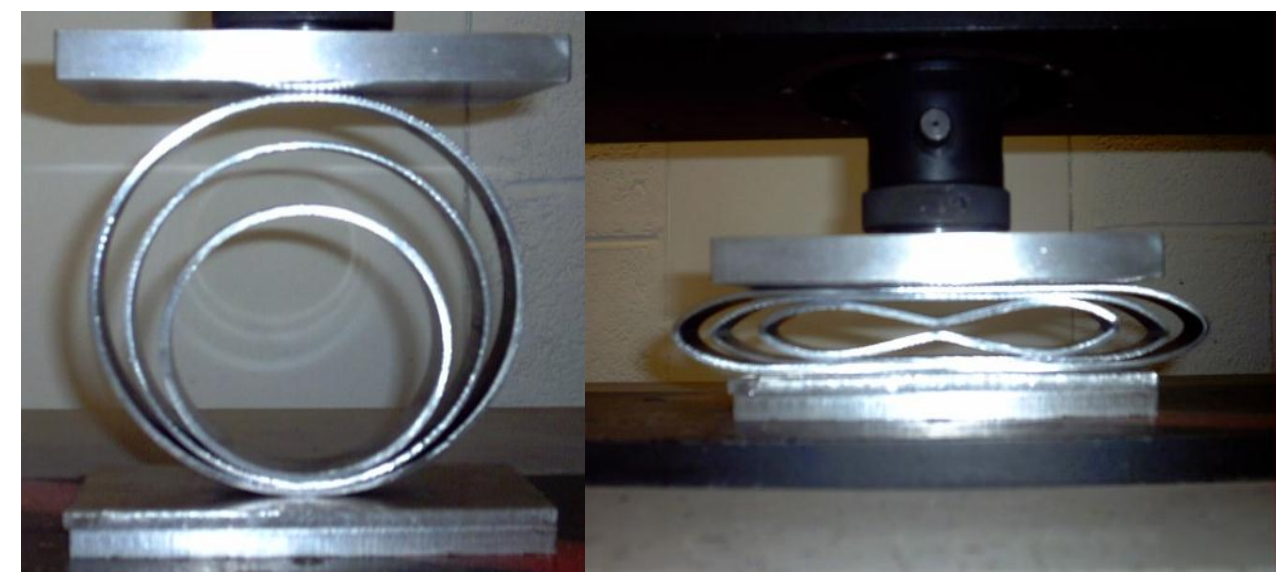

Fig. 9a. Initial and final stages of compression for a 3 tube assembly with no constraints. 


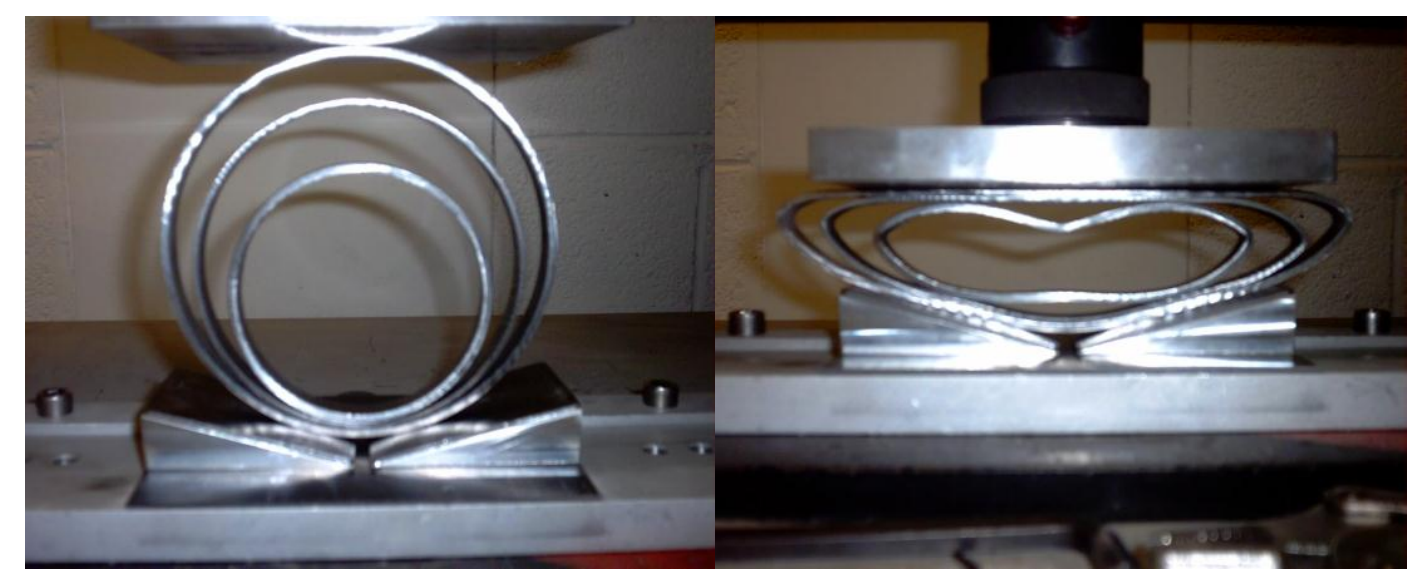

Fig. 9b. Initial and final stage of crushing for a 3 tube system with 15 degrees inclined constraints. 


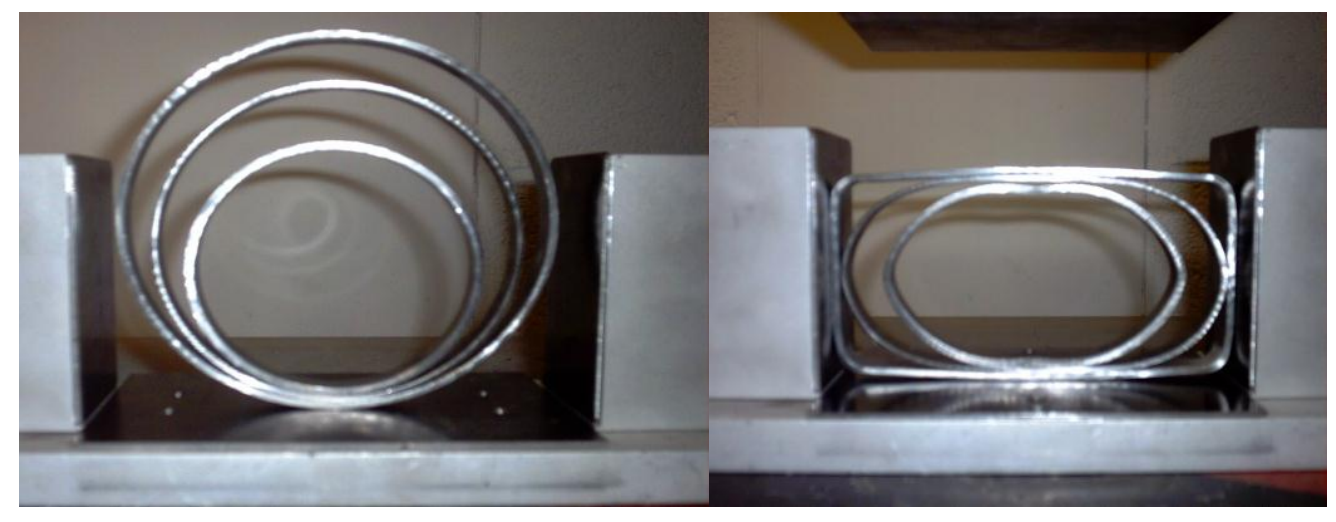

Fig. 10a. Initial and final stages of system compressed between rigid platens and vertical side constraints. 


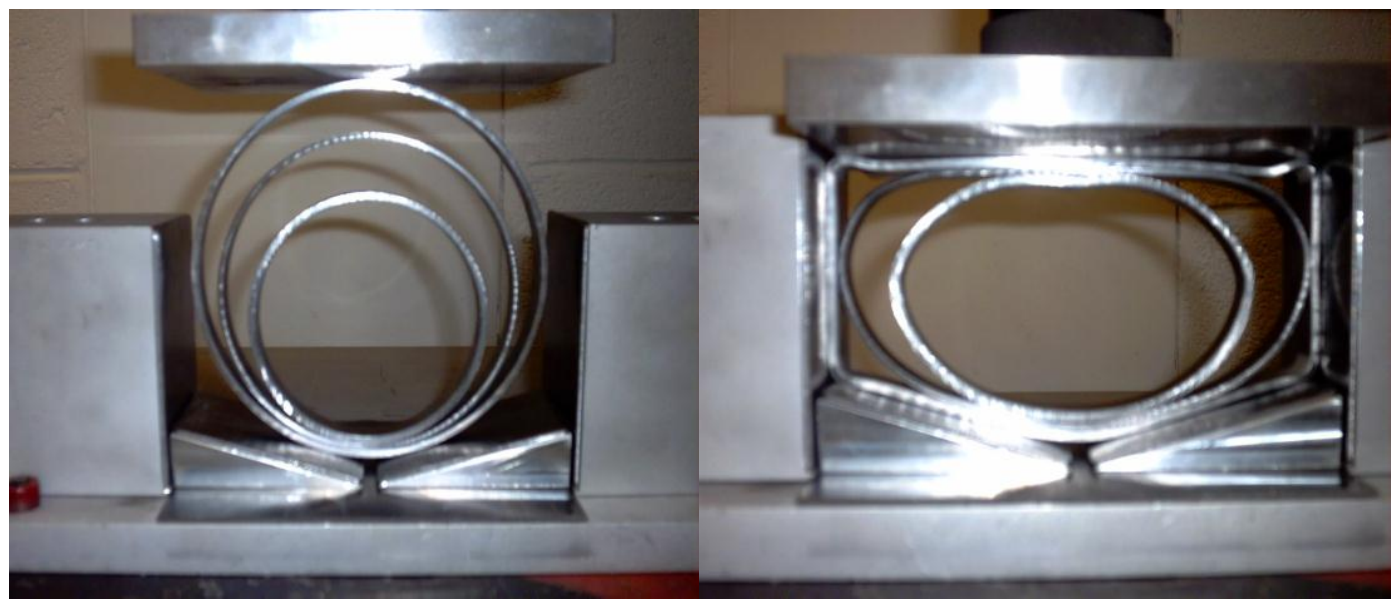

Fig. 10b. Initial and final stages of compression for 3-tube system with vertical and inclined constraints. 


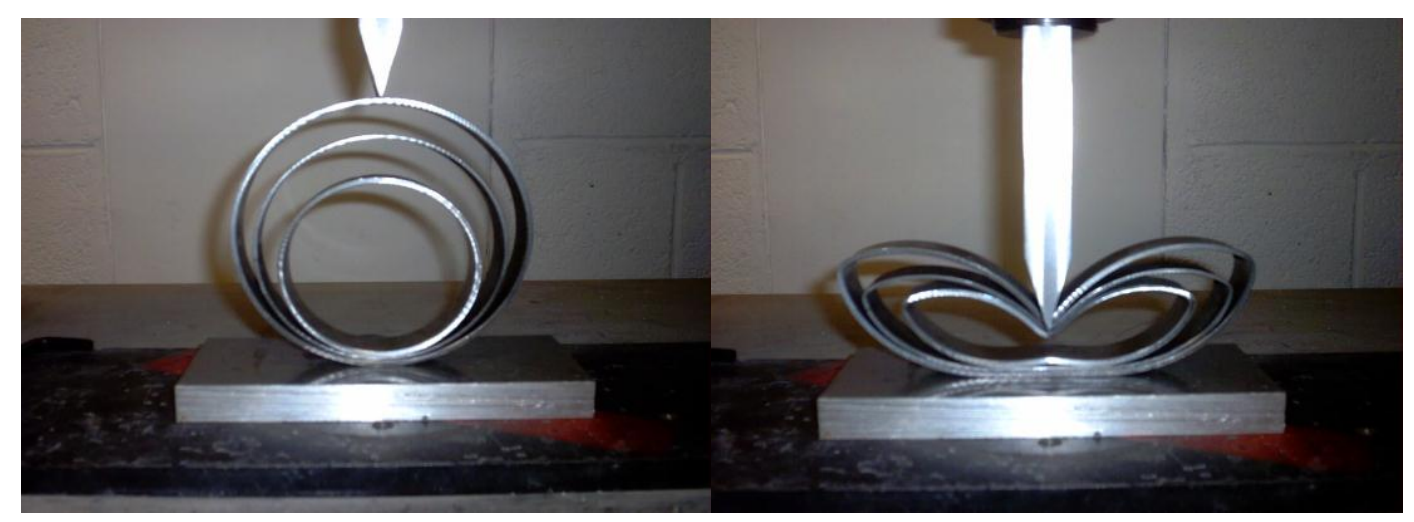

Fig. 11a. Initial and final stages of compression for a 3 tube system with no constraints. 


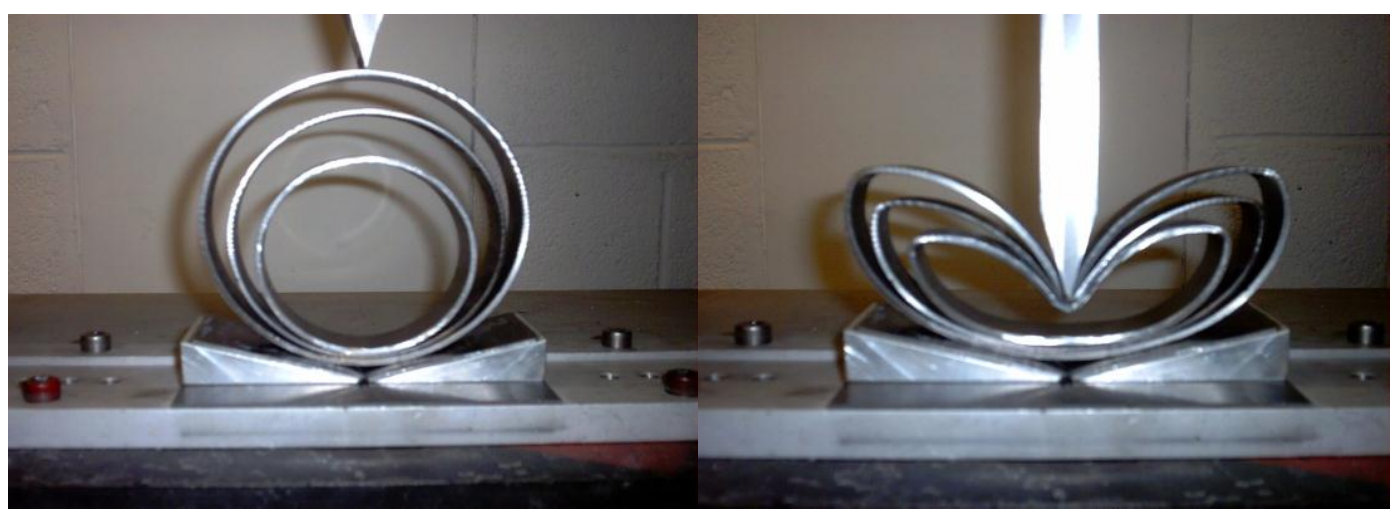

Fig. 11b. Initial and Final stages of compression for a 3 tube system with 15 degree inclined constraints. 


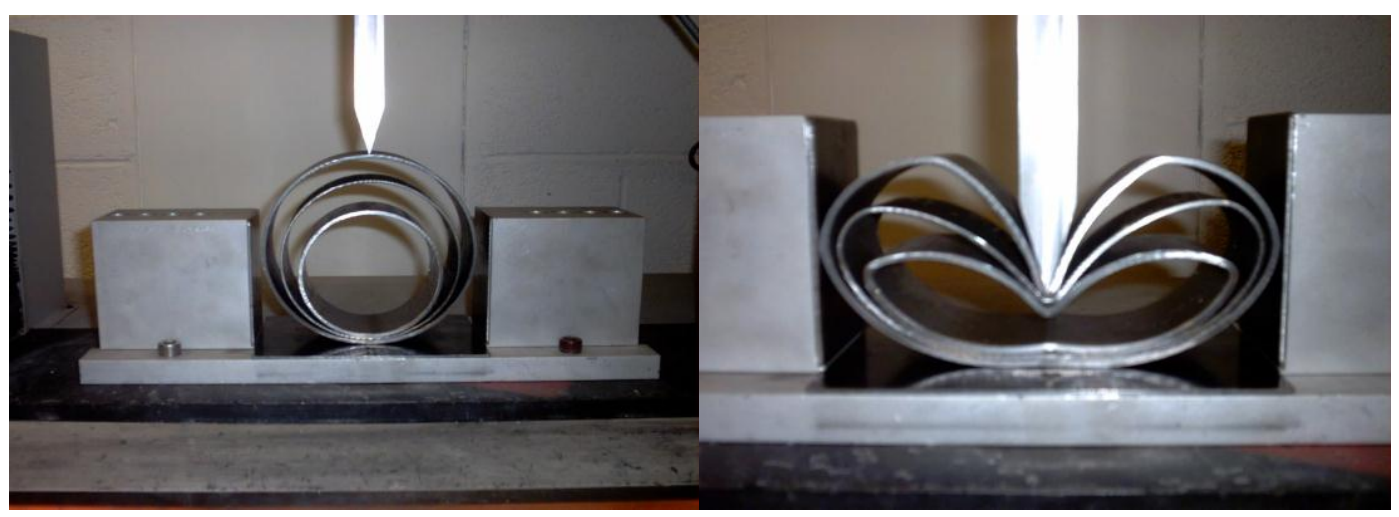

Fig. 12a. Initial and final stages of compression for a 3 tube system with vertical side constraints. 


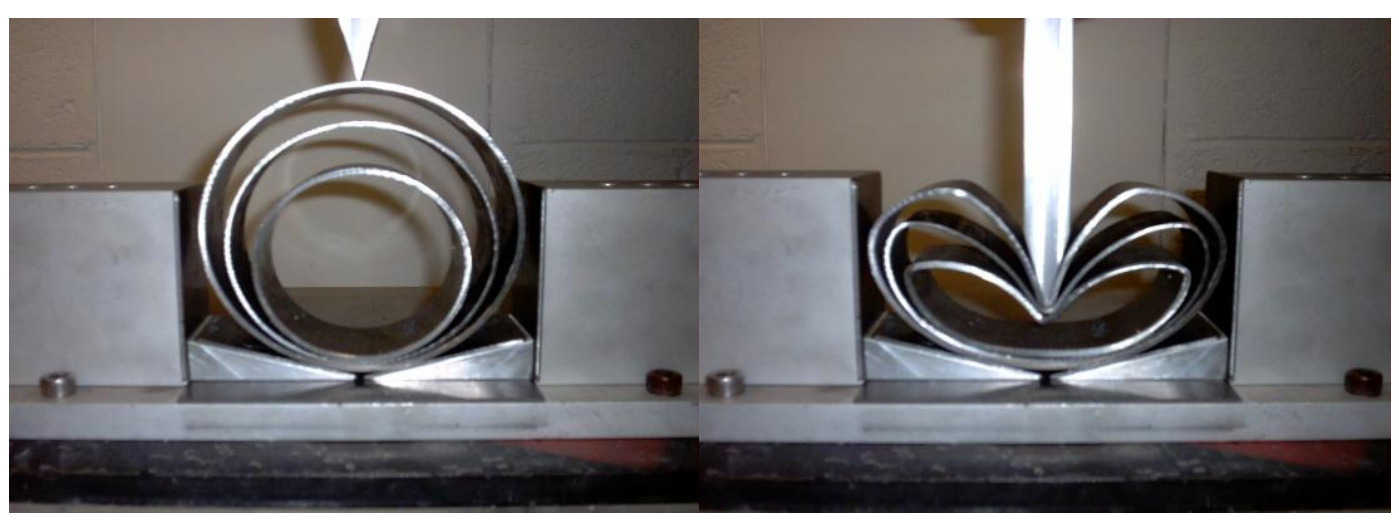

Fig. 12b. Initial and final stages of compression for a 3 tube system with in 15 degrees inclined constraints. 


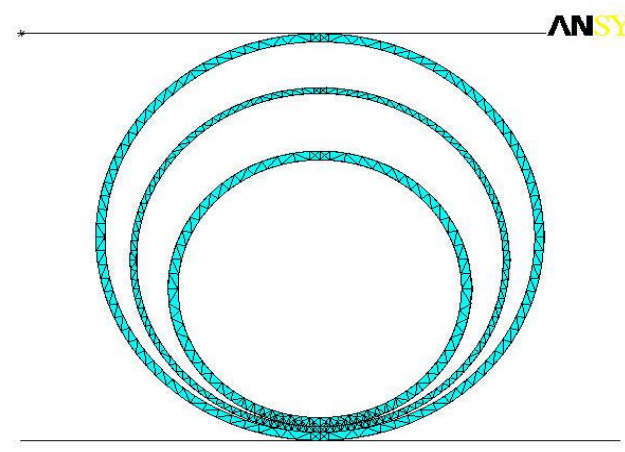

Fig. 13a. Graphic display of the initial and final stages of compression of deformation for a 3 tube system compressed between rigid plates using finite element methods. 


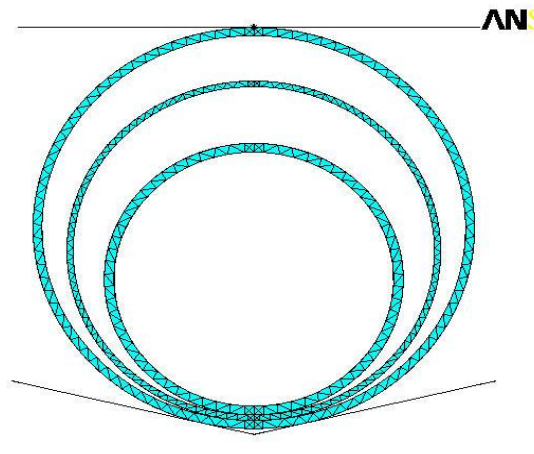

Fig. 13b. Graphic display of the initial and final stages of compression for a 3 tube system compressed between rigid plates and 15 degrees inclined constraints. 

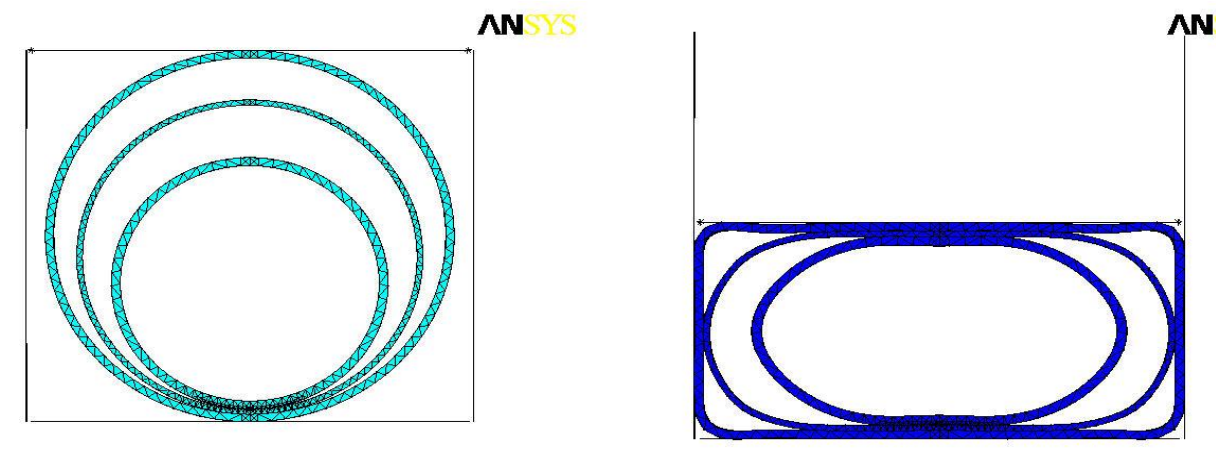

Fig. 14a. Graphic display of the initial and final stages of compression for a 3 tube system compressed between rigid plates and vertical side constraints using finite element methods. 

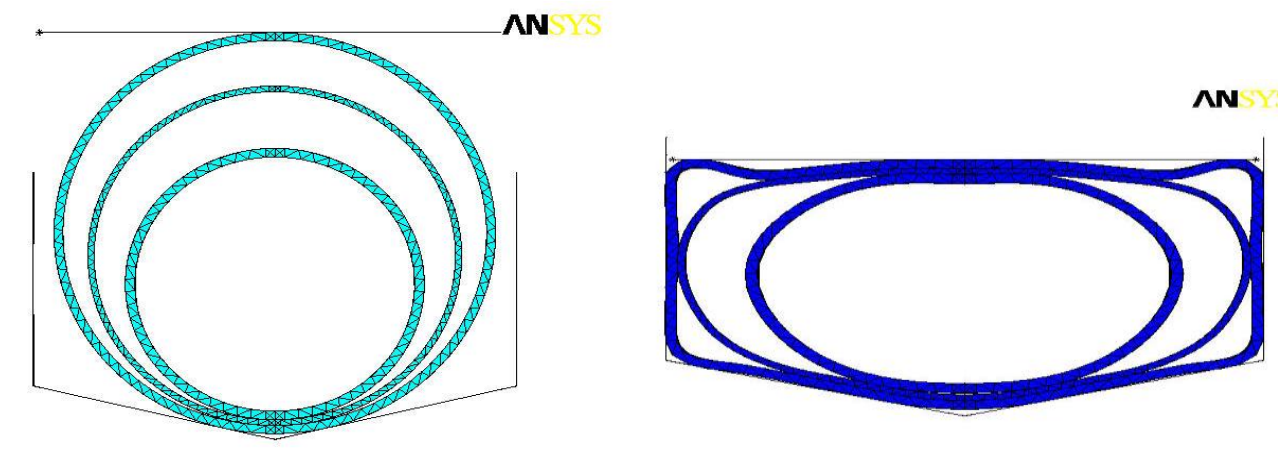

Fig. 14b. Graphic display of the initial and final stages of compression for a 3 tube system compressed between rigid plates and vertical and inclined side constraint. 


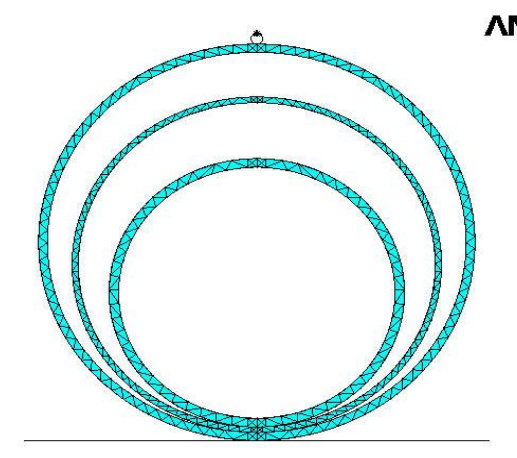

Fig. 15a. Graphic display of the various stages of deformation for a 3 tube system compressed with a point indenter and no constraints. 


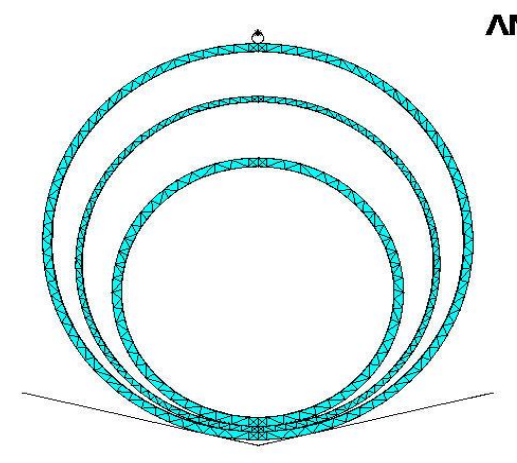

Fig. 15b. Graphic display of the various stages of deformation for a 3 tube system compressed between rigid plates and 15 degrees inclined constraints. 

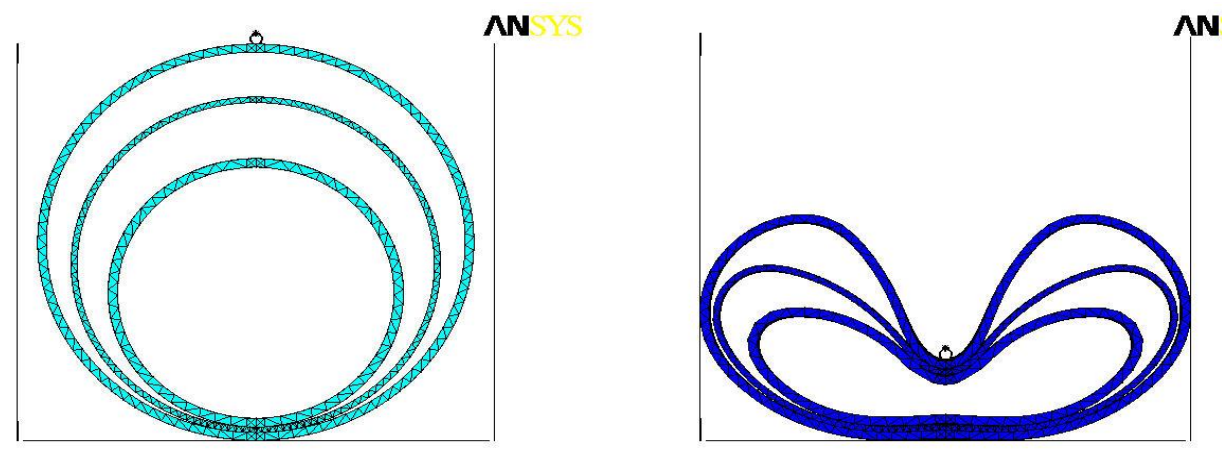

Fig. 16a. Graphic display of the various stages of deformation for a 3 tube system compressed with a point indenter and vertical constraints. 

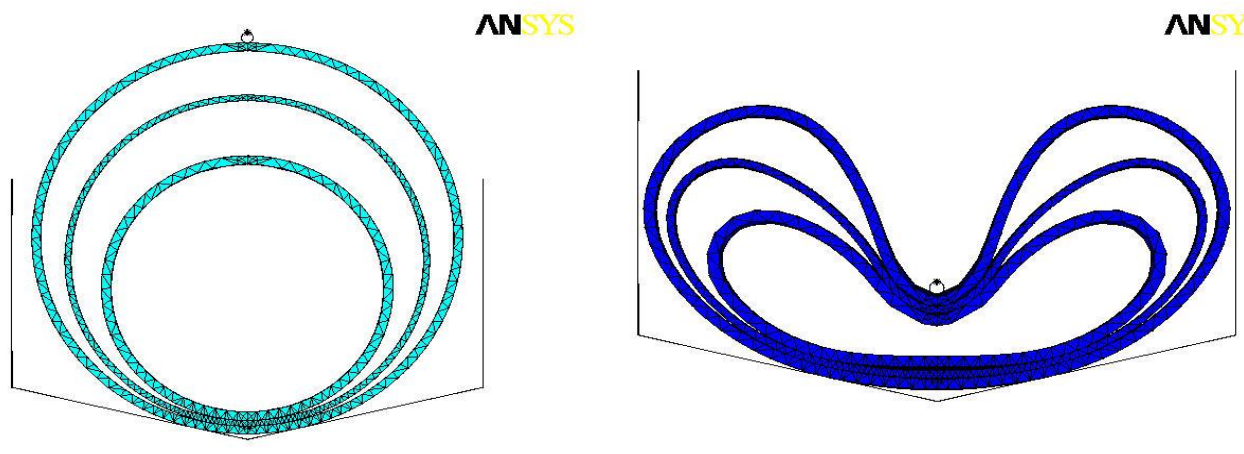

Fig. 16b. Graphic display of the various stages of deformation for a 3 tube system compressed with a point indenter and 15 degrees inclined and vertical constraints. 
Table 1. Geometric and mechanical properties of the short tubes used.

\begin{tabular}{|c|c|c|c|c|c|}
\hline Outer & Thickness & Mass & Yield Stress & Elastic & Plastic \\
\hline Diameter & {$[\mathrm{mm}]$} & {$[\mathbf{K g}]$} & [MPa] & Modulus & Modulus \\
\hline$[\mathrm{mm}]$ & & & & [GPa] & [GPa] \\
\hline 150 & 3 & 0.65 & 400 & 200 & 1.5 \\
\hline 127 & 2.11 & 0.39 & 450 & 200 & 1.5 \\
\hline 101.6 & 3.25 & 0.47 & 450 & 200 & 1.5 \\
\hline
\end{tabular}


Table 2. Various performance indicators used to describe the behaviour of the nested systems.

\begin{tabular}{|c|c|c|c|c|}
\hline System type. & $\begin{array}{c}\text { Geometric } \\
\text { Efficiency } e_{g}[\%]\end{array}$ & $\begin{array}{l}\text { Energy Efficiency } \\
\qquad e_{E}[\%]\end{array}$ & $\begin{array}{c}\text { Specific Energy at } \\
\text { final stage } \\
S_{s}^{c}[\mathrm{Nm} / \mathrm{kg}]\end{array}$ & $\begin{array}{c}\text { Weight } \\
\text { Effectiveness } \\
W_{e f f}\end{array}$ \\
\hline$\overline{\mathbf{A}}$ & 77 & 39 & 995@116mm & 766 \\
\hline B & 63 & 29 & $882 @ 95 \mathrm{~mm}$ & 555 \\
\hline $\bar{C}$ & 46 & 12 & 930@69mm & 427 \\
\hline D & 41 & 8 & 1120@61mm & 459 \\
\hline $\mathbf{E}$ & 80 & 70 & 769@120mm & 615 \\
\hline $\mathbf{F}$ & 69 & 60 & 682@103mm & 470 \\
\hline $\mathbf{G}$ & 75 & 67 & 781@113mm & 586 \\
\hline $\mathbf{H}$ & 70 & 62 & 735@105mm & 515 \\
\hline
\end{tabular}

